\title{
A STUDY OF QUALITY OF SLEEP IN PEOPLE WITH MENTAL ILLNESS WITH SIGNIFICANT CLINICAL IMPROVEMENT
}

\author{
Gireesh Kumar Miryala1, Siva Anoop Yella², Vijay Kumar Bandaru ${ }^{3}$
}

${ }_{1}^{1}$ Associate Professor, Department of Psychiatry, Kakathiya Medical College, Warangal, Telangana, India.

2Junior Resident, Department of Psychiatry, Osmania Medical College, Hyderabad, Telangana, India.

3Junior Resident, Department of Psychiatry, Osmania Medical College, Hyderabad, Telangana, India.

\section{ABSTRACT}

\section{BACKGROUND}

Sleep disturbances have become a common co-morbid condition in psychiatric illnesses. Even after treating the immediate psychiatric symptoms, some individuals have difficulties in sleep and their quality of sleep is altered which further affects functional disability and quality of life of the patient.

Aims and Objectives- To study the quality of sleep in people with mental illness with significant clinical improvement.

\section{MATERIALS AND METHODS}

Clinical Global Impression- Global Improvement (CGI-I) Scale and Pittsburgh Sleep Quality Index (PSQI) scale were used for the study. Patients attending review outpatient department of Tertiary Care Hospital, Hyderabad were selected as subjects, many of them being psychotic spectrum, mood disorder and alcohol-dependent patients. Patients who scored $<4$ on CGI-I scale were taken as subjects and PSQI was calculated. Out of 109 population size, 86 subjects meeting CGI-I score < 4 were taken and PSQI for each subject was calculated. PSQI total $</=5$ indicates good sleep quality. PSQI total $>/=5$ indicates poor sleep quality. SPSS Software version 22 was used. Statistical analysis using Chi-square test, ANOVA was done, and Pearson co-relation test was done to find relation between sleep quality and medicine-induced sleep.

\section{RESULTS}

PSQI total was $</=5$ in 33 patients. PSQI total was $>5$ in 53 patients. PSQI mean was calculated to be 7.65. Pearson Co-relation Coefficient (PCC) for sleep quality and medicine-induced sleep was found to be 0.179 . Age is negatively co-related to medicineinduced sleep and positively co-related to CGI-I score.

\section{CONCLUSION}

Out of 109 patients, 86 patients scored < 4 on CGI-I scale, 33 patients were having good sleep quality and 53 patients were having poor sleep quality. PCC of 0.179 indicates positive co-relation between sleep quality and medicine-induced sleep. Further research is needed to study co-morbid sleep disturbances in psychiatric illnesses.

\section{KEY WORDS}

Quality of Sleep, Pittsburgh Sleep Quality Index, Clinical Global Impression- Global Improvement Scale, Psychiatric Patients. HOW TO CITE THIS ARTICLE: Miryala GK, Yella SA, Bandaru VK. A study of quality of sleep in people with mental illness with significant clinical improvement. J. Evolution Med. Dent. Sci. 2018;7(22):2654-2659, DOI: 10.14260/jemds/2018/597

\section{BACKGROUND}

Sleep disturbances have become a common co-morbid condition in psychiatric illnesses. Even after treating the immediate psychiatric symptoms, some individuals have difficulties in sleep and their quality of sleep is altered which further affects functional disability and quality of life.(1) Hence, there is a need to assess the Quality of Sleep in clinically improved psychiatric patients, so that the extent of sleep disturbances can be assessed and treated appropriately. There appears to be a cyclical relationship between sleep disturbance and medical or psychiatric illness. For example, worsening sleep problems can lead to exacerbated psychiatric symptoms and daytime distress. (2)

'Financial or Other Competing Interest': None.

Submission 15-04-2018, Peer Review 15-05-2018,

Acceptance 21-05-2018, Published 28-05-2018.

Corresponding Author:

Dr. Gireesh Kumar Miryala,

Flat No. 101, Pooja Residency,

Besides MNR School,

Chandanagar, Hyderabad-500050,

Telangana.

E-mail:drgireesh1881@gmail.com

DOI: $10.14260 /$ jemds $/ 2018 / 597$
Sleep disturbance is prevalent in schizophrenia, during both psychosis and remission. Schizophrenia patients suffer from at least one type of sleep complaint such as difficulty falling asleep, early morning awakening, awakening during the night, not sleeping soundly and having increased time in bed.(3)

Bipolar disorder (BD) is a serious, chronic and recurring condition in which sleep disturbance is a common symptom regardless of phase of illness. Sleep disturbance is frequently the last symptom to resolve as an affective episode finishes, although for many individuals it does not fully remit and remains a persistent inter-episode symptom. Reduction in sleep time is a cardinal feature of mania.(4) This observation, and evidence that sleep deprivation can precipitate mania in patients with bipolar disorder has led to the hypothesis that sleep reduction is central to the evolution of mania.(5) According to this model, individuals with bipolar disorder respond to sleep loss with elevation in mood, energy and goal-directed behaviour along with a further decrease in sleep. Sleep disturbance is the most recognised prodromal symptom of mania( ${ }^{(4)}$ and is one of its diagnostic criteria, and improvement in sleep is an important therapeutic target in mania as it often heralds the re-stabilisation of the current mental state.(6) Likewise, sleep problems are reported in $50-$ 
$90 \%$ of patients with syndromal or sub-syndromal depressive symptoms in BD.(6)

Insomnia is extremely common among those who suffer from alcohol dependence and/ or abuse, where its prevalence is estimated to be $36-72 \%$. It is believed that the sleep disturbance stems from a rebound of wakefulness occurring as the effects of alcohol, which has sleep promoting effects wear off.(7-9) Several longitudinal studies suggest that those with insomnia are at increased risk for the development of subsequent alcohol use problems compared to those without disturbed sleep.(10)

\section{Aims and Objectives \\ Aims}

To study the quality of sleep in people with mental illness with significant clinical improvement.

\section{Objectives}

- To differentiate people with mental illness into good quality sleepers and poor-quality sleepers.

- To find out the relation between quality of sleep and medicine-induced sleep.

\section{MATERIALS AND METHODS}

Study Design

Cross-sectional study.

\section{Sampling Technique}

Convenient sampling method.

\section{Period of Study}

2 months.

\section{Place of Study}

Tertiary Care Hospital, Hyderabad.

\section{Source of Data}

Patients attending Review Outpatient Department of Tertiary Care Hospital, HYD.

Tools

Pittsburgh Sleep Quality Index.

The PSQI is an effective instrument used to measure the quality and patterns of sleep. It differentiates "poor" from "good" sleep by measuring seven subscales: Subjective Sleep Quality, Sleep Latency, Sleep Duration, Habitual Sleep Efficiency, Sleep Disturbances, Use of Sleeping Medication and Daytime Dysfunction over the last month. The client selfrates each of these seven areas of sleep by answering nine questions. Scoring of answers is based on a zero to three scale, and a score of three reflects the negative extreme on the Likert Scale. A global sum of " 5 " or greater indicates a "poor" sleeper. The PSQI has internal consistency and a reliability coefficient (Cronbach's alpha) of 0.83 for its seven components. Numerous studies using the PSQI have supported high validity and reliability.(11)

\section{Clinical Global Impression- Global Improvement Scale (CGI-I Scale)}

The CGI global improvement measure (CGI-I) is rated from 1 (very much improved) to 7 (very much worse). CGI improvement scale (CGI-I) has been widely utilised as an efficacy measure in clinical drug trials in different mental disorders [e.g. depression, schizophrenia]. Its popularity is mainly based on its conciseness and easiness of administration. It is widely accepted and some studies presented evidence arguing that the CGI is a valid assessment instrument.(12)

IBM SPSS software is used for statistical analysis version 22.

\section{Inclusion Criteria}

- Age: 18 - 60 years

- Gender- Male and Female.

- Patients scoring < 4 on CGI-I scale.

\section{Exclusion Criteria}

- Patients with organic illnesses.

- Patients with primary insomnia.

\section{Procedure}

109 participants attending Review Outpatient Department of Institute of Mental Health, Hyderabad were included in the study. Patients mainly included were those belonging to psychotic spectrum disorders, mood disorders, mental retardation and alcoholism. CGI-I (Clinical Global Impression scale was used to select patients and those who have scored $<4$ were taken as subjects. A total of 86 patients have scored $<4$ on CGI-I scale. Pittsburgh Sleep Quality Index (PSQI) scale was used to assess the quality of sleep in the patients who have scored $<4$ on CGI-I scale. PSQI score for each of the participant was obtained and differentiated into poor sleep quality and good sleep quality patients.

\section{Statistical Analysis}

PSQI mean was obtained using IBM SPSS software for Statistical analysis version 22. Socio-demographic data of the patients was obtained using frequencies, descriptive statistics. Chi-square test was done to verify differences between the categorical variables. Means for scales were calculated. ANOVA test was done to find out variance between continuous variables. Pearson co-relation test was done to see the co-relations between different parameters.

P-value was set at significance of $<0.05$.

\section{RESULTS}

Our study revealed many important findings. Table 1 shows the frequency and percentage of males and females in our study. Table 2 shows the Chi-square test for the sociodemographic data of the patients comparing the variable sex with marital status, occupation, socio-economic status, education and domicile status of the patients. Chi-square was statistically insignificant for the diagnosis groups. Table 3 shows the Means and Standard deviations of Age, PSQI, CGI-I and Medicine-induced sleep for both females and males. Table 4 shows the Means and Standard Deviations of Age, PSQI, CGI-I and Medicine-induced sleep for Schizophrenia, BPAD (Bipolar Affective Disorder), Alcohol related disorders, Mental Retardation, Depression, Schizoaffective disorder and Psychosis NOS. It was found out that only Age is a significant parameter and F-values obtained indicate that there is no much variance in the PSQI, Age, CGI-I and medicine-induced 
sleep values which is shown in Table 5. Figure 1 shows Mean plot for Age distribution among various Diagnosis groups. Table 6 shows the co-relations between Age, PSQI, CGI-I, medicine-induced sleep. Pearson's co-relation test was done. Age is negatively co-related to medicine-induced sleep, which implies that higher the age lower is the need for medications to induce sleep. PSQI score is positively co-related to CGI-I score, which indicates that better the improvement in the clinical symptoms the better the quality of sleep.
Positive co-relation was also found in between PSQI and medicine-induced sleep, but the test is statistically insignificant probably due to small sample size.

Out of 109 participants, 86 patients have met CGI-I rating score $<4$. Out of 86 patients, Global PSQI score was $</=5$ in 33 patients and Global PSQI score was $>5$ in 53 patients indicating good quality of sleep in 33 patients and poor quality of sleep in 53 patients as shown in Table 7.

\begin{tabular}{|c|c|c|}
\hline & Frequency & Percentage \\
\hline Males & 46 & 53.5 \\
\hline Females & 40 & 46.5 \\
\hline \multicolumn{2}{r}{} \\
\hline
\end{tabular}

\begin{tabular}{|c|c|c|c|c|c|c|}
\hline & & \multicolumn{2}{|c|}{ Sex } & \multirow{2}{*}{$\begin{array}{c}\text { Chi-Square } \\
\text { Value }\end{array}$} & \multirow{2}{*}{ P-value } & \multirow{2}{*}{ Total } \\
\hline & & Male & Female & & & \\
\hline \multirow{3}{*}{ Marital Status } & Married & 24 & 28 & \multirow{3}{*}{7.470} & \multirow{3}{*}{0.024} & 52 \\
\hline & Unmarried & 20 & 7 & & & 27 \\
\hline & $\begin{array}{l}\text { Divorced/ } \\
\text { Separated }\end{array}$ & 2 & 5 & & & 7 \\
\hline \multirow{2}{*}{ Education } & Literate & 25 & 13 & \multirow{2}{*}{4.141} & \multirow{2}{*}{0.042} & 38 \\
\hline & Illiterate & 21 & 27 & & & 48 \\
\hline \multirow{6}{*}{ Occupation } & Semi-profession & 5 & 1 & \multirow{6}{*}{14.304} & \multirow{6}{*}{0.014} & 6 \\
\hline & \begin{tabular}{|c|} 
Clerical, Shop owner, \\
Farmer
\end{tabular} & 7 & 3 & & & 10 \\
\hline & Skilled worker & 9 & 6 & & & 15 \\
\hline & Semi-skilled worker & 14 & 6 & & & 20 \\
\hline & Unskilled worker & 6 & 7 & & & 13 \\
\hline & Unemployed & 5 & 17 & & & 22 \\
\hline \multirow{4}{*}{ Socio-Economic Status } & Upper middle & 9 & 5 & \multirow{4}{*}{3.709} & \multirow{4}{*}{0.295} & 14 \\
\hline & Lower middle & 18 & 11 & & & 29 \\
\hline & Upper lower & 7 & 6 & & & 13 \\
\hline & Lower & 12 & 18 & & & 30 \\
\hline \multirow{3}{*}{ Domicile } & & & & \multirow{3}{*}{3.017} & \multirow{3}{*}{0.082} & 32 \\
\hline & Urban & 21 & 11 & & & \\
\hline & Rural & 25 & 29 & & & 54 \\
\hline \multicolumn{7}{|c|}{ Table 2. Socio-Demographic Data of Patients } \\
\hline
\end{tabular}

\begin{tabular}{|c|c|c|c|c|c|}
\hline \multicolumn{2}{|r|}{ Sex } & Age & PSQI* & CGI-I** & Medicine-Induced Sleep \\
\hline \multirow{3}{*}{ Females } & Mean & 36.65 & 8.75 & 1.90 & 1.525 \\
\hline & $\mathrm{N}$ & 40 & 40 & 40 & 40 \\
\hline & Std. Deviation & 10.798 & 4.695 & .871 & 1.2808 \\
\hline \multirow{3}{*}{ Males } & Mean & 35.91 & 6.70 & 1.91 & .674 \\
\hline & $\mathrm{N}$ & 46 & 46 & 46 & 46 \\
\hline & Std. Deviation & 9.647 & 3.921 & .839 & 1.0340 \\
\hline \multirow{3}{*}{ Total } & Mean & 36.26 & 7.65 & 1.91 & 1.070 \\
\hline & $\mathrm{N}$ & 86 & 86 & 86 & 86 \\
\hline & Std. Deviation & 10.144 & 4.395 & .849 & 1.2251 \\
\hline
\end{tabular}

PSQI*- Pittsburgh Sleep Quality Index, CGI-I**- Clinical Global Impression- Improvement, N- Frequency

\begin{tabular}{|c|c|c|c|c|c|}
\hline \multicolumn{2}{|c|}{ Diagnosis } & Age & PSQI $^{*}$ & CGI-I** $^{*}$ & Medicine-Induced Sleep \\
\hline \multirow{3}{*}{ Schizophrenia } & Mean & 36.40 & 7.37 & 1.80 & .971 \\
\cline { 2 - 6 } & $\mathrm{N}$ & 35 & 35 & 35 & 35 \\
\cline { 2 - 6 } & Std. Deviation & 8.510 & 4.222 & .868 & 1.2244 \\
\hline \multirow{3}{*}{ BPAD $^{\#}$} & Mean & 34.19 & 8.00 & 1.92 & 1.115 \\
\cline { 2 - 6 } & $\mathrm{N}$ & 26 & 26 & 26 & .796 \\
\cline { 2 - 6 } & Std. Deviation & 7.808 & 4.858 & 1.77 & .615 \\
\hline \multirow{3}{*}{ Alcohol Related } & Mean & 41.62 & 6.38 & 13 & 13 \\
\cline { 2 - 6 } & $\mathrm{N}$ & 13 & 13 & .832 & 1.0439 \\
\cline { 2 - 6 } & Std. Deviation & 14.009 & 3.305 & .798 \\
\hline
\end{tabular}




\begin{tabular}{|c|c|c|c|c|c|}
\hline \multirow{3}{*}{ Depression } & Mean & 36.80 & 9.20 & 2.60 & 1.600 \\
\hline & $\mathrm{N}$ & 5 & 5 & 5 & 5 \\
\hline & Std. Deviation & 12.677 & 5.541 & .548 & 1.5166 \\
\hline \multirow{3}{*}{ Mental Retardation } & Mean & 44.33 & 8.00 & 1.67 & 1.000 \\
\hline & $\mathrm{N}$ & 3 & 3 & 3 & 3 \\
\hline & Std. Deviation & 15.144 & 4.583 & 1.155 & 1.0000 \\
\hline \multirow{3}{*}{ Schizoaffective Disorder } & Mean & 22.50 & 14.50 & 3.00 & 2.000 \\
\hline & $\mathrm{N}$ & 2 & 2 & 2 & 2 \\
\hline & Std. Deviation & .707 & .707 & .000 & 1.4142 \\
\hline \multirow{3}{*}{ Psychosis NOS } & Mean & 26.00 & 5.00 & 2.00 & 3.000 \\
\hline & $\mathrm{N}$ & 2 & 2 & 2 & 2 \\
\hline & Std. Deviation & 5.657 & 1.414 & 1.414 & .0000 \\
\hline \multirow{3}{*}{ Total } & Mean & 36.26 & 7.65 & 1.91 & 1.070 \\
\hline & $\mathrm{N}$ & 86 & 86 & 86 & 86 \\
\hline & Std. Deviation & 10.144 & 4.395 & .849 & 1.2251 \\
\hline \multicolumn{6}{|c|}{$\begin{array}{l}\text { Table 4. Table showing Means and Standard Deviations of Age, PSQI, } \\
\text { CGI-I and Medicine-Induced Sleep for Various Diagnoses }\end{array}$} \\
\hline
\end{tabular}

PSQI*- Pittsburgh Sleep Quality Index, CGI-I**- Clinical Global Impression- Improvement, N- Frequency, BPAD\#- Bipolar Affective Disorder.

\begin{tabular}{|c|c|c|}
\hline & F & P-value \\
\hline Age & 2.238 & .048 \\
\hline PSQI $^{*}$ & 1.295 & .269 \\
\hline CGI-I** $^{*}$ & 1.334 & .252 \\
\hline Medicine-Induced Sleep & 1.581 & .164 \\
\hline Table 5. ANOVA (Analysis of Variance) amongst different Diagnostic Groups \\
\hline
\end{tabular}

PSQI*- Pittsburgh Sleep Quality Index, CGI-I**- Clinical Global Impression- Improvement, F- ANOVA Coefficient Value.

\begin{tabular}{|c|c|c|c|c|c|}
\hline \multicolumn{7}{|c|}{ Correlations } \\
\hline & Age & PSQI & CGI-I & Medicine Induced Sleep \\
\hline Age & Pearson Correlation(r) p-value & 1 & -.0350 .748 & .0550 .617 & -.213 .049 \\
\hline PSQI $^{*}$ & Pearson Correlation & -.0350 .748 & 1 & .578 .000 & $.1790 . .098$ \\
\hline CGI-I** $_{\text {Medicine }}^{*}$ & Pearson Correlation & .0550 .617 & .578 .000 & 1 & .0520 .637 \\
Induced Sleep & Pearson Correlation & -.213 .049 & .1790 .098 & .0520 .637 & 1 \\
\hline \multicolumn{7}{|c|}{ Table 6. Correlations between Age, PSQI, CGI-I, Medicine-Induced Sleep } \\
\hline
\end{tabular}

PSQI*- Pittsburgh Sleep Quality Index, CGI-I** - Clinical Global Impression - Improvement

\begin{tabular}{|c|c|c|c|}
\hline & Males & Females & Total \\
\hline PSQI $</=5$ & $22(50 \%)$ & $11(26.2 \%)$ & 33 \\
\hline PSQI $>5$ & $22(50 \%)$ & $31(73.8 \%)$ & 53 \\
\hline \multicolumn{2}{|l}{ Table 7. Frequency and Percentages of PSQI Scores of Males and Females } \\
\hline
\end{tabular}

\section{DISCUSSION}

This study differentiated good sleepers and poor sleepers. PSQI score was $</=5$ in 33 subjects and $>5$ in 53 subjects. PSQI score was $</=5$ in 22 males and $>5$ in 22 males. PSQI score was $</=5$ in 11 females and $>5$ in 31 females. Quality of sleep was equally good and poor in males, i.e. $50 \%$ were having good quality sleep and $50 \%$ were having poor quality sleep. Whereas in females $26.2 \%$ were good quality sleepers and $73.8 \%$ were poor quality sleepers. A study conducted by Michael Ritsner et al 2004, also differentiated between good sleepers and poor sleepers and also compared the quality of sleep with quality of life,(13) which was not done in our study. In this study it was found out that diagnosis is independent of marital status, occupation, socio-economic status, education and domicile status of the patient. ANOVA test done indicates that there is no much variance in the PSQI, Age, CGI-I and medicine-induced sleep values. Pearson co-relation test revealed that higher the age of the individual, lower the need for medications to induce sleep. Positive co-relation between age and CGI-score indicates that higher the age of the individual, more the global improvement in symptoms which further implies that older people have good prognosis and younger age groups have bad prognosis. Statistically insignificant p-value was obtained between Age and PSQI score in this study when compared to a study done by Brabbins et al 1993(14) and Taylor et al 2005,(15) in which older adults had a decreased quality of sleep. With positive co-relation between PSQI score and CGI-I score, it explains that with clinical improvement in psychiatric symptoms, the quality of sleep also improves. This study also showed statistical insignificance between sleep quality and medicineinduced sleep. Sleep quality is good in patients who are using medications, either benzodiazepines or anti-psychotics, but are not dependent on them for sleep. This study also showed that Quality of Sleep is the same independent on the diagnosis of the patient, i.e. quality of sleep is equally affected 
in all the patients in this study. But among the diagnoses Schizoaffective disorder patients had worse quality of sleep when compared to Schizophrenic group, which was also seen in a study conducted by John R Hofstetter et al 2005 in their study of Quality of Sleep in patients with schizophrenia and its association with quality of life and coping.(16)

An early investigation conducted by Detre T et al in 1966 on psychiatric inpatients found that $83 \%$ of 12 acutely ill schizophrenia patients and $47 \%$ of 17 patients with chronic psychosis had at least one type of sleep complaint.(17) But the study has not shown that quality of sleep has effect on the improvement in symptoms, which was shown in our study. A study conducted by Royuela AMJ et al 2002 in a sample of 44 adults with schizophrenia reported poor sleep quality at a rate of $52 \%$ using the Pittsburgh Sleep Quality Index,(18) which in our study also poor sleep quality was seen in 35 schizophrenic patients.

A group study conducted by Morin et al in 2011 revealed that sleep disturbance among BD participants was overwhelmingly greater when measured by self-report.(19) Several studies conducted by Skoloda TE et al and Brower KJ et al suggest that those with alcoholism often use alcohol as a means to treat sleep difficulties.(20) There was no literature found comparing the quality of sleep and medicine-induced sleep in alcoholics, which was done in this study.

A substantial number of studies conducted by Benca RM et al in 1992, Haffmans PM et al in 1994 and Palmese LB et al in 2011 have reported that sleep continuity disturbances and poor sleep quality detrimentally affect quality of life in patients with schizophrenia even while on stable medication regimens,(21,22) which was found to be statistically insignificant in our study.

\section{Drawbacks}

Small sample size.

\section{CONCLUSION}

Positive co-relation between medicine-induced sleep and sleep quality indicates that sleep quality is good in patients who are using medications, either benzodiazepines or antipsychotics and are dependent on them for sleep. Psychiatric morbidity deters the patient from normal sleep and leads to sleep disturbances and hence the need to assess their sleep quality and further treat the sleep disturbances.

All these observations suggest the need for research into the treatment of co-morbid sleep disturbances and psychiatric disorders.

There appears to be a greater likelihood of successful therapy if the sleep difficulty and co-morbid disorder (i.e. mood disorder, alcoholism or schizophrenia) are simultaneously targeted for treatment.

\section{Future Research}

- Further study is required to be done as to why males are good sleepers and females are poor sleepers.

- Future research is aimed to find out the prevalence rates of sleep disturbances in bipolar, schizophrenia and alcoholism patients.

\section{ACKNOWLEDGEMENT}

I would like to thank all the subjects who have participated in this study. I would like to thank the Institute for its support and the residents who have supported me all throughout. Special thanks to my resident Dr. Siva Anoop Yella, who has helped me bring out this paper and helped me throughout this study. And also, thanks to my resident Dr. Vijay Kumar for his contribution in this study.

\section{REFERENCES}

[1] Benca RM, Obermeyer WH, Thisted RA, et al. Sleep and psychiatric disorders. A meta-analysis. Archives of General Psychiatry 1992;49(8):651-8.

[2] Krystal AD, Thakur M, Roth T. Sleep disturbance in psychiatric disorders: effects on function and quality of life in mood disorders, alcoholism and schizophrenia. Ann Clin Psychiatry 2008;20(1):39-46.

[3] Wehr TA, Goodwin FK, Wirz-Justice A, et al. 48-hour sleep-wake cycles in manic-depressive illness: naturalistic observations and sleep deprivation experiments. Arch Gen Psychiatry 1982;39(5):559-65.

[4] Wehr TA, Sack DA, Rosenthal NE. Sleep reduction as a final common pathway in the genesis of mania. Am J Psychiatry 1987;144(2):201-4.

[5] Plante DT, Winkelman JW. Sleep disturbance in bipolar disorder: therapeutic implications. Am J Psychiatry 2008;165(7):830-43.

[6] Tsuno N, Besset A, Ritchie K. Sleep and depression. J Clin Psychiatry 2005;66(10):1254-69.

[7] Baekeland F, Lundwall L, Shanahan TJ, et al. Clinical correlates of reported sleep disturbance in alcoholics. Q J Stud Alchol 1974;35(4):1230-41.

[8] Brower KJ, Aldrich MS, Robinson EA, et al. Insomnia, self-medication and relapse to alcoholism. Am J Psychiatry 2001;158(3):399-404.

[9] Brower KJ. Insomnia, alcoholism and relapse. Sleep Med Rev 2003;7(6):523-39.

[10] Breslau N, Roth T, Rosenthal L, et al. Sleep disturbance and psychiatric disorders: a longitudinal epidemiologic study of young adults. Biological Psychiatry 1996;39(6):411-8.

[11] Buysse DJ, Reynolds CF III, Monk TH, et al. The Pittsburgh Sleep Quality Index: a new instrument for psychiatric practice and research. Psychiatry Res 1989;28(2):193-213.

[12] Forkmann T, Scherer A, Boecker M, et al. The clinical global impression scale and the influence of patient or staff perspective on outcome. BMC Psychiatry 2011;11:83.

[13] Ritsner M, Kurs R, Ponizovsky A, et al. Perceived quality of life in schizophrenia: relationships to sleep quality. Quality of Life Research 2004;13(4):783-91.

[14] Brabbins CJ, Dewey ME, Copeland JRM, et al. Insomnia in the elderly: prevalence, gender differences and relationships with morbidity and mortality. International Journal of Geriatric Psychiatry 1993;8(6):473-80.

[15] Taylor DT, Lichstein KL, Durrence HH, et al. Epidemiology of insomnia, depression and anxiety. Sleep 2005;28(11):1457-64.

[16] Hofstetter JR, Lysaker PH, Mayeda AR. Quality of sleep in patients with schizophrenia is associated with quality of life and coping. BMC Psychiatry 2005;5:13. 
[17] Detre T. Sleep disorder and psychosis. Can Psychiatr Assoc J 1966;(Suppl 11):169-77.

[18] Royuela A, Macias JA, Gil-Verona JA, et al. Sleep in schizophrenia: a preliminary study using the Pittsburgh Sleep Quality Index. Neurobiol SleepWakefulness Cycle 2002;2(2):37-9.

[19] Morin CM, Colecchi C, Stone J, et al. Behavioral and pharmacological therapies for late-life insomnia. Journal of the American Medical Association 1999;281(11):991-9.
[20] Skoloda TE, Alterman AI, Gottheil E. Sleep quality reported by drinking and non-drinking alcoholics. In: Gottheil EL, Elmsford NY, eds. Addiction research and treatment. NewYork: Pergamon Press 1979: p. 102-12.

[21] Haffmans PM, Hoencamp E, Knegtering HJ, et al. Sleep disturbance in schizophrenia. $\mathrm{Br} \mathrm{J}$ Psychiatry 1994;165(5):697-8.

[22] Palmese LB, DeGeorge PC, Ratliff JC, et al. Insomnia is frequent in schizophrenia and associated with night eating and obesity. Schizophr Res 2011;133(1-3):23843. 